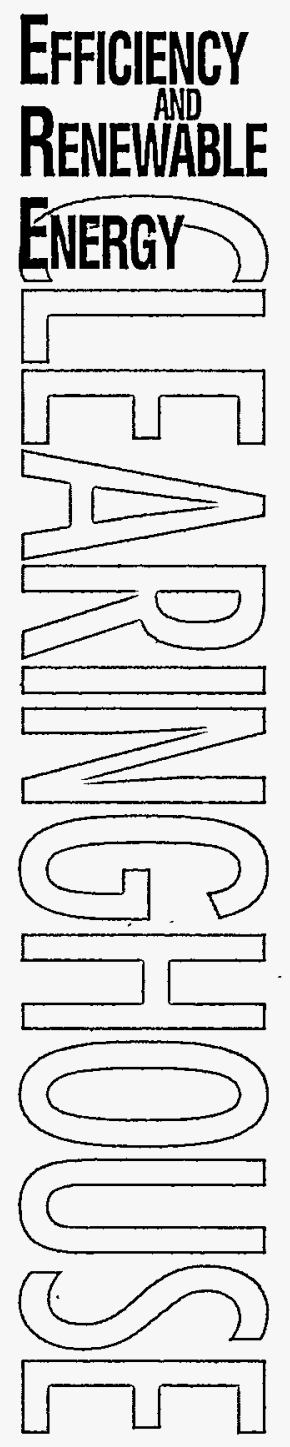

\title{
Energy-Efficient Windows
}

Windows bring light, warmth, and beauty into buildings and give a feeling of openness and space to living areas. They can also be major sources of heat loss in the winter and heat gain in the summer. In 1990 alone, the energy used to offset unwanted heat losses and gains through windows in residential and commercial buildings cost the United States $\$ 20$ billion (one-fourth of all the energy used for space heating and cooling). However, when properly selected and installed, windows can help minimize a home's heating, cooling, and lighting costs. This publication describes one option-energy-efficient windows-available for reducing a home's heating and cooling energy requirements.

\section{Controlling Air Leaks.}

When air leaks around windows, energy is wasted. Energy is also transferred

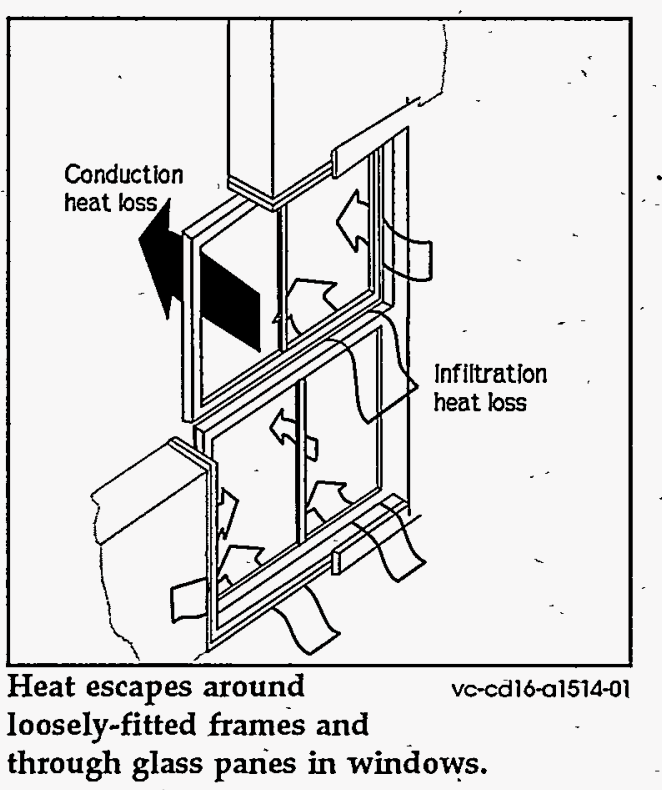

through the centers, edges, and frames of windows. Eliminating or reducing these paths of heat flow can greatly improve the energy efficiency of. windows and, ultimately, of homes. Several options are available to reduce air leaks around windows; the least expensive options are caulking and weatherstripping, followed by replacing window frames.

\section{Caulking and Weatherstripping}

Caulks are airtight compounds (usually latex or silicone) that fill cracks and holes. Before applying new caulk, old caulk or paint residue remaining around a window should be removed using a putty knife, stiff brush, or special solvent. After old caulk is removed, new caulk can then be applied to all joints in the window frame and the joint between the frame and the wall. The best time to apply caulk is during dry weather when the outdoor temperature is above $45^{\circ} \mathrm{Fahr}$ enheit $\left(7.2^{\circ}\right.$ Celsius). Low humidity is important during application to prevent cracks from swelling with moisture. Warm temperatures are also necessary so the caulk will set properly and adhere to the surface.

Weatherstripping is a narrow piece of metal, vinyl, rubber, felt, or foam that seals the contact area between the fixed and movable sections of a window joint. It should be applied between the sash and the frame, but should not interfere with the operation of the window. For more information on caulking and weatherstripping, contact the Energy Efficiency and Renewable Energy Clearinghouse (EREC).

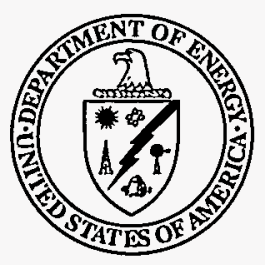

This document was produced for the U.S. Department of Energy (DOE) by the National Renewable Energy Laboratory (NREL), a DOE national laboratory. The document was produced by the Technical Information Program, under the DOE Office of Energy Efficiency and Renewable Energy. The Energy Efficiency and Renewable Energy Clearinghouse (EREC) is operated by NCI Information Systems, Inc., for NREL/DOE. The statements contained herein are based on information known to EREC and NREL at the time of printing. No recommendation or endorsement of any product or service is implied if mentioned by EREC. 


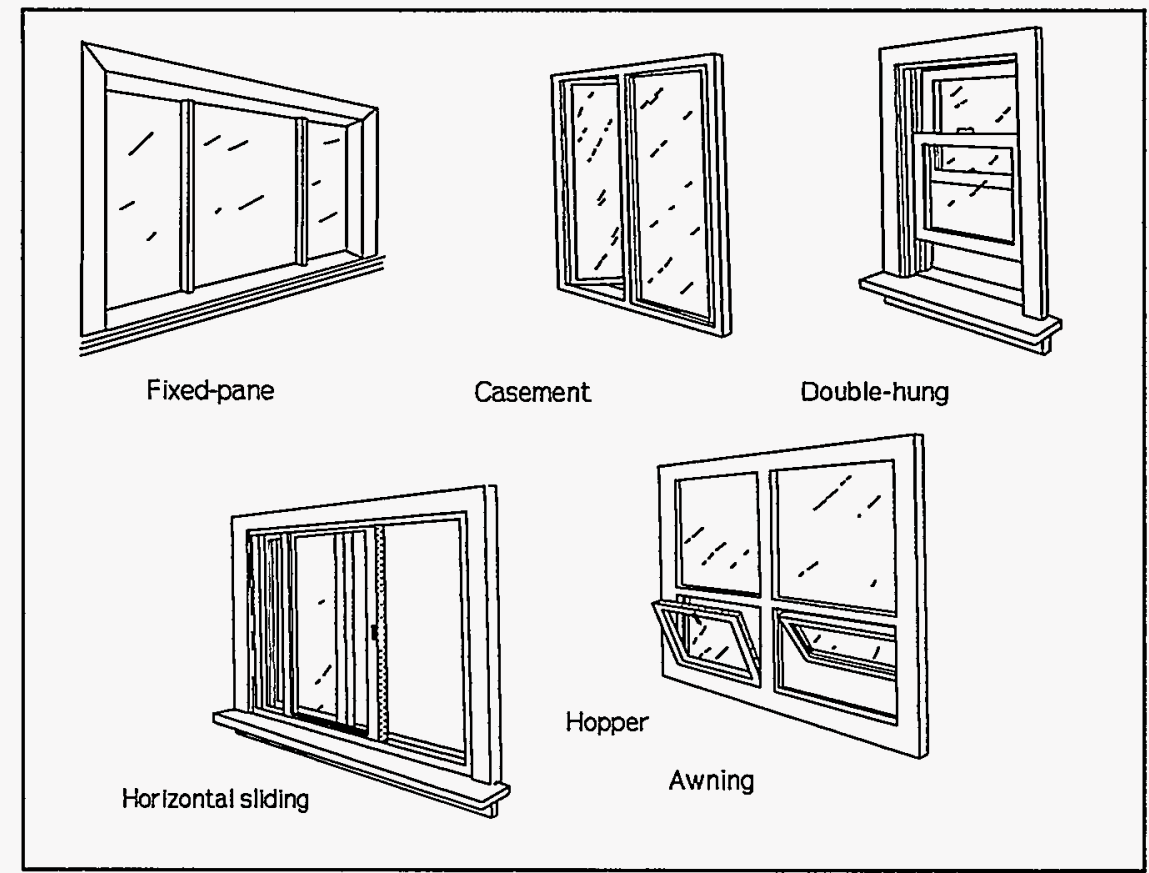

Frame types can affect the energy efficiency of a window.

\section{Replacing Window Frames}

The type and quality of the window frame usually affect a window's air infiltration and heat loss characteristics. Many window frames are available-all with varying degrees of energy efficiency. Some of the more common window frames are fixed-pane, casement, double- and single-hung, horizontal sliding, hopper, and awning.

resistance to

heat flow, or

$R$-value, is

high, it will

lose less heat

than one

with a lower

$R$-value.

Casement, awning, and hopper windows with compression seals are moderately airtight and provide good compression seals allow about half as much air leakage as double-hung and horizontal sliding windows with sliding seals.

Double-hung windows have top and bottom sashes (the sliding sections of the window) and can be opened by pulling up the lower sashes or pulling down the upper sash. Although they are among the most popular type of window, double-hung windows can be inefficient because they are often leaky. Single-hung windows are somewhat better because only one sash moves. Horizontal sliding windows are like double-hung windows except that the sashes are located on the left and right edges rather than on the tops and bottoms. Horizontal sliding windows open on the side and are especially suitable for spaces that require a long, narrow view. These windows, however, usually provide minimal ventilation and, like double-hung windows, can be quite leaky.

\section{Reducing Heat Loss and Condensation}

Manufacturers usually represent the energy efficiency of windows in terms of their U-values (conductance of heat) or their R-values (resistance to heat flow). If a window's R-value is high, it will lose less heat than one with a lower R-value. Conversely, if a window's U-value is low, it will lose less heat than one with a higher U-value. In other words, U-values are the reciprocals of $R$-values (U-value $=1 / R$-value). Most window manufacturers use $\mathrm{R}$-values in rating their windows. ventilation when opened. Casement windows open sideways with hand cranks. Awning windows are similar to casement windows except that their hinges are located at the tops of the windows instead of at the sides. Hopper windows are inverted versions of awning windows with their hinges located at the bottom. Windows with
Usually, window R-values range from 0.9 to 3.0 (U-values range from 1.1 to 0.3 ), but some highly energy-efficient exceptions also exist. When comparing different windows, you should ensure that all U- or R-values listed by manufacturers: (1) are based on current standards set by the American Society of Heating, Refrigeration, and AirConditioning Engineers (ASHRAE), (2) are calculated for the entire 


\section{DISCLAIMER}

This report was prepared as an account of work sponsored by an agency of the United States Government. Neither the United States Government nor any agency thereof, nor any of their employees, make any warranty, express or implied, or assumes any legal liability or responsibility for the accuracy, completeness, or usefulness of any information, apparatus, product, or process disclosed, or represents that its use would not infringe privately owned rights. Reference herein to any specific commercial product, process, or service by trade name, trademark, manufacturer, or otherwise does not necessarily constitute or imply its endorsement, recommendation, or favoring by the United States Government or any agency thereof. The views and opinions of authors expressed herein do not necessarily state or reflect those of the United States Government or any agency thereof. 


\section{DISCLAIMER}

Portions of this document may be illegible in electronic image products. Images are produced from the best available original document. 


\section{Traditionally, clear glass has been the primary material available for window panes in homes.}

window, including the frame, and not just for the center of the glass, and (3) represent the same size and style of window.

The following five factors affect the $\mathrm{R}$-value of a window.

- The type of glazing material (e.g., glass, plastic, treated glass)

- The number of layers of glass

- The size of the air space between the layers of glass

- The thermal resistance or conductance of the frame and spacer materials

- The "tightness" of the installation (i.e., air leaks-see previous discussion).

\section{Types of Glazing Materials}

Traditionally, clear glass has been the primary material available for window panes in homes. However, in recent years, the market for glazing -or cutting and fitting window panes into frameshas changed significantly. Now several types of special glazings are available that can help control heat loss and condensation.

Low-emissivity (low-e) glass has a special surface coating to reduce heat transfer back through the window. These coatings reflect from $40 \%$ to $70 \%$ of the heat that is normally transmitted through clear glass, while allowing the full amount of light to pass through.

Heat-absorbing glass contains special tints that allow it to absorb as much as $45 \%$ of the incoming solar energy, reducing heat gain. Some of the absorbed heat, however, passes through the window by conduction and reradiation.

Reflective glass has been coated with a reflective film and is useful in controlling solar heat gain during the summer. It also reduces the passage of light all year long, and, like heatabsorbing glass, it reduces solar transmittance.

Plastic glazing materials-acrylic, polycarbonate, polyester, polyvinyl fluoride, and polyethylene-are also widely available. Plastics can be stronger, lighter, cheaper, and easier to cut than glass. Some plastics also have higher solar transmittance than glass. However, plastics tend to be less durable and more susceptible to the effects of weather than is glass.

Storm windows can increase the efficiency of single-pane windows, the least energy-efficient type of glazing. The simplest type of storm window is a plastic film taped to the inside of the window frame. These films are usually available in prepackaged kits. Although plastic films are easily installed and removed, they are easily damaged and may reduce visibility. Rigid or semirigid plastic sheets such as plexiglass, acrylic, polycarbonate, or fiberreinforced polyester can be fastened directly to the window frame or mounted in channels around the frame-usually on the outside of the building. These more durable materials are also available in kits.

For more information about advanced types of glazing materials, contact EREC.

\section{Layers of Glass and Air Spaces}

Standard single-pane glass has very little insulating value (approximately $\mathrm{R}-1$ ). It provides only a thin barrier to the outside and can account for considerable heat loss and gain. Traditionally, the approach to improve a window's energy efficiency has been to increase the number of glass panes in the unit, because multiple layers of glass increase the window's ability to resist heat flow. 


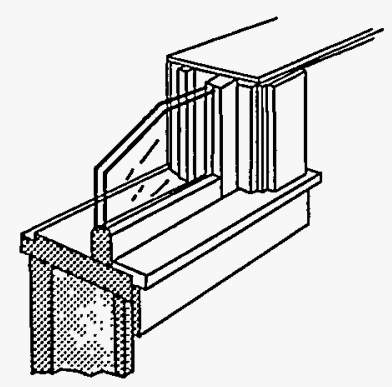

Double pane

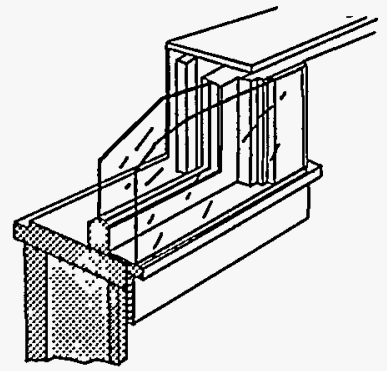

Inside storm window

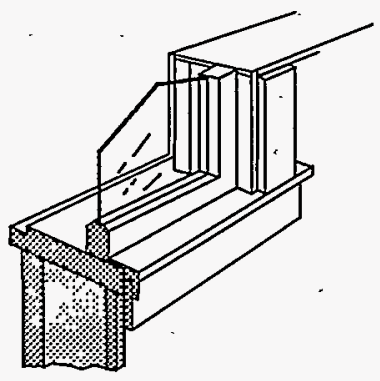

Single pane

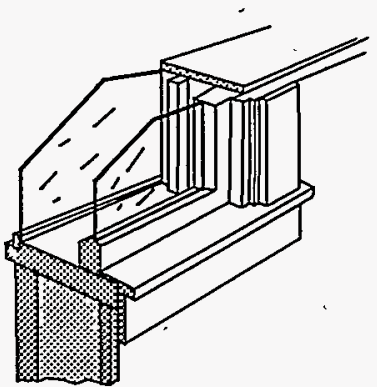

Outside storm window

Double-pane windows are usually more efficient than single-pane or storm windows.

vc-col16-a1514-04

Window frames are

available in a

variety of materials, including aluminum, wood, vinyl, and fiberglass.
Double- or triple-pane windows have insulating air- or gas-filled spaces between each pane. Each layer of glass and the air spaces resist heat flow. The width of the air spaces between the panes is important, because air spaces that are too wide (more than $5 / 8$ inch or 1.6 centimeters) or too narrow (less than $1 / 2$ inch or 1.3 centimeters) have lower R-values (i.e., they allow too much heat transfer). Advanced, multipane windows are now manufactured with inert gases (argon or krypton) in the spaces between the panes because these gases transfer less heat than does air.

Multipane windows are considerably more expensive than single-pane windows and limit framing options because of their increased weight.

\section{Frame and Spacer Materials}

Window frames are available in a variety of materials including aluminum, wood, vinyl, and fiberglass. Frames may be primarily composed of one material, or they may be a combination of different materials such as wood and vinyl. Each frame material has its advantages and disadvantages.

Though ideal for customized window design, aluminum frames cause conductive heat loss (i.e., they have low R-values) and condensation. However, thermal breaks made of insulating plastic strips placed between the inside and outside of the frame and sash greatly improve the thermal resistance of aluminum frames.

Wood frames have higher R-values, are unaffected by temperature extremes, and are less prone to condensation, but they require considerable maintenance in the form of periodic painting. If wood frames are not properly protected from moisture, they can warp, crack, and stick.

Vinyl window frames, which are made primarily from polyvinyl chloride (PVC), offer many advantages. They are available in a wide range of styles and shapes, have moderate to high R-values, are easily customized, are competitively priced, require low maintenance, and mold easily into almost any shape. But vinyl frames are not strong or rigid, which limits the weight of glass that can be used. In addition, vinyl frames can soften, warp, twist, and bow.

Fiberglass frames are relatively new and are not yet widely available. They have the highest $R$-values of all frames; thus, they are excellent for insulating and will not warp, shrink, swell, rot, or corrode. Fiberglass frames can be made in a variety of colors and can hold large expanses of glass. Some fiberglass frames are hollow; others are filled with fiberglass insulation.

Spacers are used to separate multiple panes of glass within the windows. Although metal (usually aluminum) spacers are commonly installed to separate glass in multipane windows, they conduct heat. During cold weather, 


\section{Many types of \\ windows and \\ window films are \\ available that \\ serve different \\ purposes.}

the thermal resistance around the edge of a window is lower than that in the center; thus, heat can escape, and condensation can occur along the edges. To alleviate these problems, one manufacturer has developed a multipane window using a 1/8-inch-wide (0.32 centimeters-wide) PVC foam separator placed along the edges of the frame. Like other multipane windows, these use metal spacers for support, but because the foam separator is secured on top of the spacer between the panes, heat loss and condensation are reduced. Several window manufacturers now sandwich foam separators, nylon spacers, and insulation materials such as polystyrene and rockwool between the glass inside their windows.

\section{Additional Options for Reducing Heat Loss and Gain through Windows}

Movable insulation, such as insulating shades, shutters, and drapes, can be applied on the inside of windows to reduce heat loss in the winter and heat gain in the summer. Shading devices, such as awnings, exterior shutters, or screens, can be used to reduce unwanted heat gain in the summer.

In most cases, these window treatments are more cost-effective than energyefficient window replacements and should be considered first. Additional information on window treatments is available from EREC.

\section{Conclusion}

Reducing heat loss or gain in homes often includes either improving existing windows or replacing them. Lowcost options available for improvement are caulking, weatherstripping, retrofit window films, and window treatments. Replacing windows will involve the purchase of new materials, which should adhere to certain energy efficiency standards.

Different combinations of frame style, frame material, and glazing can yield very different results when weighing energy efficiency and cost. For example, a fixed-pane window is the most air-tight and the least expensive; a window with a wood frame is likely to have less conductive heat loss than one with an aluminum frame; double-pane, low-e window units are just as efficient as triple-pane untreated windows, but cost and weigh less.

No one window is suitable for every application. Many types of windows and window films are available that serve different purposes. Moreover, you may discover that you need two types of windows for your home because of the directions that your windows face and your local climate. To make wise purchases, first examine your heating and cooling needs and prioritize desired features such as daylighting, solar heating, shading, ventilation, and aesthetic value. 


\section{Source List}

The following resources provide more information on energy-efficient windows.

American Architectural Manufacturers Association (AAMA)

2700 River Road, Suite 118

Des Plaines, IL 60018

(708) 202-1350

Developed a testing procedure [AAMA 1503] for measuring the thermal transmission properties of aluminum-, vinyl-, and wood-framed windows.

American Society of Heating, Refrigerating, and Air-Conditioning Engineers (ASHRAE) 1791 Tullie Circle, NE Atlanta, GA 30329 (404) 636-8400 ASHRAE's Handbook of Fundamentals contains tables citing heat transfer, light transmittance, and shading properties for various window types and materials.

National Fenestration Rating Council (NFRC)

962 Wayne Avenue, Suite 750

Silver Spring, MD 20910

(301) 589-6372

Developed the Procedure for Determining Fenestration Product Thermal Properties (NFRC 100-91). These procedures are now being used in NFRC's window certification and efficiency labeling programs, which have already been adopted by three states.

National Wood Window and Door Association

1400 East Touhy Avenue

Des Plaines, IL 60018-3305

(708) 299-5200

Issues seals of approval for manufacturers of wood-framed windows.
U.S. Department of Energy (DOE) Building Systems and Materials Division EE-421

1000 Independence Avenue, SW

Washington, DC 20585

(202) 586-9214

Developed the WINDOW computer program, which aids window manufacturers and building designers in optimizing the thermal and daylighting performance of window systems. For their certification and labeling programs, the NFRC uses the WINDOW computer program and DOEsupported research and testing to determine the thermal and optical properties of windows.

\section{Vinyl Window and Door Institute}

355 Lexington Avenue

New York, NY 10017

(212) 351-5400

Developed performance standards and certification program for manufacturers of vinyl-framed windows.

\section{Reading List}

"Low-E Glass-Why the Coating Is Where It Is," Energy Design Update, pp. 5-7, March 1990.

"No Pane, No Gain (Window Technology: Part One)," Popular Science, pp. 92-98, June 1993.

"Through the Glass Darkly," Popular Science, pp. 80-87, July 1993. 